IEEE Journal of Oceanic Engineering

October 2016, Volume 41, Issue 4, Pages 744-752

http://dx.doi.org/10.1109/JOE.2016.2552779

http://archimer.ifremer.fr/doc/00342/45275/

(c) 2016 IEEE - All rights reserved

\title{
Long-Term In Situ Survey of Reactive Iron Concentrations at the EMSO-Azores Observatory
}

\author{
Laes-Huon Agathe ${ }^{1}$, Cathalot Cecile ${ }^{1}$, Legrand Julien ${ }^{1}$, Tanguy Virginie ${ }^{2}$, Sarradin Pierre-Marie ${ }^{1}$ \\ ${ }^{1}$ Institut Carnot Edrome, Centre de Brest,Departement Ressources Physiques et Ecosystemes de Fond \\ de Mer, Ifremer, Plouzane 29280, France \\ 2 Institut Carnot Edrome, Centre de Brest,Departement Ressources Physiques et Ecosystemes de Fond \\ de Mer, Ifremer, Plouzane 29280, France
}

*Corresponding author : Agathe Laes-Huon, email address : Agathe.laes@ifremer.fr

\begin{abstract}
:
A study of the temporal dynamics of iron concentrations and temperature on a faunal assemblage at the Lucky Strike vent was performed using the Tempo ecological module at the EMSO-Azores deep-sea observatory. The CHEMINI in situ analyzer was implemented on this structure to determine reactive iron concentrations in unfiltered seawater samples along with a temperature probe. Stability tests were performed on the CHEMINI analyzer before deployment (optical module, hyperbaric tests, and deepsea calibration) for long-term in situ analysis of reactive iron (six months, 2013-2014) at the Tour Eiffel active edifice. Recorded daily, the in situ standard (25 Imu mol.L \{\}$^{\wedge}\{-1\}$ ) showed excellent reproducibility $(1.07 \%, n=522)$, confirming satisfactory analytical performance of the CHEMINI analyzer and thus validating the iron concentrations measured by the instrument. Furthermore, the analyzer proved to be reliable and robust over time. The averaged reactive iron concentration for the six-month period remained low ([Fe] $=\operatorname{text}\{7.12\} \mid \mathrm{pm}$ text $\{2.11\} \operatorname{Imu} \operatorname{mol} . \mathrm{L}\{\}^{\wedge}\{-1\}, \mathrm{n}=519$ ), but showed some noticeable variations with temperature. Reactive iron concentrations and temperature were significantly correlated emphasizing reactive iron stabilization over the time of deployment. Period spectra indicated strong tidal influence and relevant frequencies of four to five days for both variables.
\end{abstract}

\section{Introduction}

IRON (Fe) plays a key role in global biogeochemical processes. A recent study [1] has shown that iron originating from hydrothermal sources is not negligible, and may account for $9 \%$ of the dissolved iron budget in the deep ocean [2]. In addition, iron appears to be an important factor controlling community structure in hydrothermal vent ecosystems [3], [4]. Iron is, for instance, directly involved in the chemical reactions and redox processes which occur in the mixing zone of cold oxygenated seawater and hot hydrothermal fluid [5]-[8]. Hence, the distribution of iron can provide information on the processes governing metal bioavailability in hydrothermal ecosystems and its influence on the biological community structure in these singular deep-sea environments [9], [10]. Specific instruments such as in situ analyzers have been used to characterize the chemical environment of the habitats prevailing in hydrothermal vent ecosystems [11]-[19]. These analyzers are generally deployed using remotely 
operated vehicles (ROVs) for shortterm (i.e., minutes to hours) iron analyses. However, Chapin et al. [16] successfully deployed an in situ iron analyzer for one year at 1100-m depth off the coast of Hawaii. A second yearlong deployment of the Fe-OsmoAnalyzer in a low-temperature hydrothermal vent at the Axial Volcano provided the longest continuous in situ record of a chemical species in a hydrothermal system. Data showed that fluctuations in Fe concentrations were influenced primarily by tides. To our knowledge, there are no other long-term data records on in situ iron in hydrothermal ecosystems. Hydrothermal environments constitute very hostile operating conditions for marine chemical analyzers: high pressure, steep temperature and $\mathrm{pH}$ gradients make it a real challenge to operate such analytical systems for more than a few days.

In the past few years, several seafloor observatory projects (VENUS, Ocean Networks Canada, MoMAR, ESONET, MARS, etc.) have been set up to develop multidisciplinary experiments for observation and monitoring of active seafloor processes, over longer time scales than the usual discrete sampling strategies of oceanographic cruises. Cruises regularly visit hydrothermal vents but they are costly and the acquired observation records are seasonal, infrequent, and usually cover limited time periods. Hence, seafloor observatories contribute to the study of long-term (i.e., months to years) distributions of physicochemical parameters, disturbances by episodic events (increase in iron concentration, in temperature, oxygen depletion, etc.), and the associated changes in the fauna related to variation in the abiotic environment. The development of new autonomous scientific tools, suited for long-term in situ monitoring, is an essential step to ensure the success of these seafloor observatories.

Here, we present the results of long-term deployment of an iron in situ chemical analyzer (referred hereafter as "CHEMINI," standing for CHEmical MINlaturized analyzer [19]) the deep-seafloor observatoryMoMARin the Atlantic Ocean (Monitoring the Mid-Atlantic Ridge [20]). This observatory is part of the EMSO-Azores marine research infrastructure (EMSO: European Multidisciplinary Seafloor andWater Column Observatory). This platform consists of ocean observing systems for long-term, highresolution, (near)-real-time monitoring of environmental processes. One of the specific scientific objectives of this observatory is to study the temporal dynamics of a faunal assemblage and its habitat on a hydrothermal vent using an ecological module named Tempo. The Tempo ecological unit records video footage and environmental parameters. This paper describes the EMSO-Azores MoMAR observatory, the Tempo and the CHEMINI functionalities. It also presents the variations in reactive iron concentration and temperature over six months 
(August 31, 2013-February 23, 2014). In addition to the previous study [21], it focuses on the correlation between both variables and frequencies involved in resolving the temporal dynamics of this hydrothermal system.

\section{MATERIALS AND METHODS}

\section{A. The EMSO-Azores MoMAR Observatory}

The EMSO-Azores MoMAR observatory infrastructure $\left(37^{\circ} 50^{\prime} \mathrm{N}-33^{\circ} 00^{\prime} \mathrm{W}\right)$ is part of the EMSO program. ${ }^{1}$ It is focused on a multidisciplinary long-term study of hydrothermal environments at the Mid-Atlantic Ridge (MAR), and more specifically on the Lucky Strike vent field [20]. It is a permanent uncabled seafloor observatory that records seismicity, seafloor deformation, fluid flow, temperature, and seawater chemical composition. The EMSO-Azores MoMAR observatory was first deployed during the MoMARSAT cruise in October 2010 onboard the French oceanographic vessel $R / V$ Pourquoi Pas? using ROV Victor 6000. The system was then successfully serviced and redeployed in 2011, 2012, 2013, 2014, and 2015.

The infrastructure is composed of two SEA MOnitoring Nodes (SEAMON) and a surface relay buoy (BOREL). One SEAMON node, dedicated to large-scale geophysical studies, is moored on the lava lake in the Lucky Strike vent field. The other node is deployed at the base of an active edifice to study the temporal dynamics of fauna assemblages. This node is composed of the Tempo ecological module to monitor a mussel bed (main species: Bathymodiolus azoricus) located at the base of the Tour Eiffel vent (1700-m depth, referred hereafter as the Tempo sampling site). Both nodes are acoustically linked to BOREL, which is equipped with two identical backup data transmission channels (EvoLogics) to ensure uninterrupted data flow via satellite communications to the land base station at Ifremer, Brest, France. Scientific and technical data (including low-resolution photographs and absorbance spectra from CHEMINI) are transmitted daily.

\section{B. Tempo}

The structure of Tempo has already been described in [20] and [22]. Tempo is an ecological module that records video footage and physicochemical measurements. The module was upgraded for the deployment in 2013. It is driven by COmmunication and STOrage Front-end (COSTOF) and equipped with an integrated video system named SMart Ocean Observatory Video Equipment (SMOOVE, based on an Axis Q1755 HD video camera, fitted with a solid-state drive and four pressure-balanced oil-filled LED projector lights). Three housings containing 12 $\mathrm{kWh}$ of primary lithium cells $\left(\mathrm{Li}-\mathrm{SOCl}_{2}\right)$ are used to power the various sensors.

Sensors mounted on Tempo consist of 3 NKE autonomous temperature probes, a Wetlabs turbidimeter, an Aanderaa oxygen sensor, and the CHEMINI in situ analyzer for the measurement of reactive iron concentrations (Fig. 1). Optical instruments (video camera, lights, and optode) are protected by

\footnotetext{
${ }^{1}$ www.emso-fr.org
}

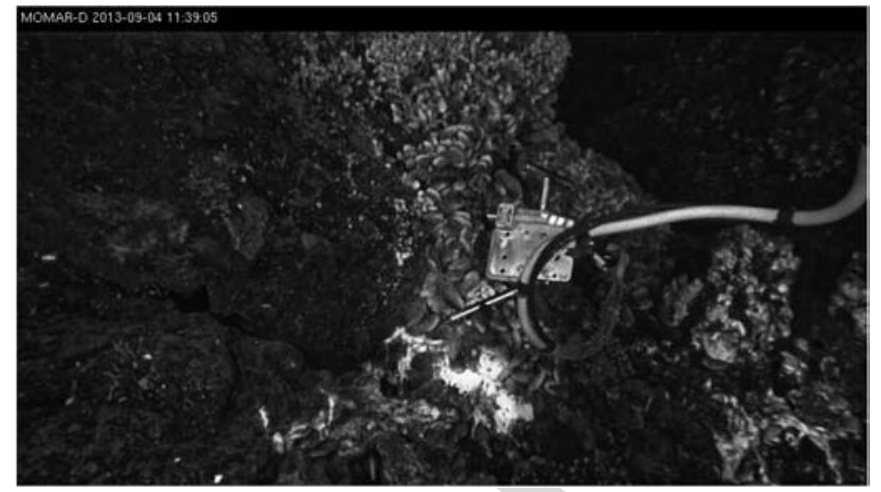

Fig. 1. Snapshot (low resolution) taken on September 4, 2013 by Tempo deployed on a mussel bed (Bathymodiolus azoricus) located at the base of Tour Eiffel edifice at 1700-m depth during the MoMAR deployment in 2013-2014. The CHEMINI sample inlet and associated temperature probe can be seen on the right-hand side of the picture.

an antibiofouling system based on local microchlorination (inhouse device [22]). Power consumption of the system totals around $10 \mathrm{kWh}$ per year (sensors, COSTOF electronic unit, and acoustic modem). The CHEMINI Fe in situ analyzer needs approximately $1.3 \mathrm{kWh}$ per year. Recorded data are stored in the COSTOF internal memory and transmitted every six hours to the Ifremer data center.

\section{CHEMINI}

CHEMINI is an in situ monoparameter analyzer that can measure various chemical concentrations in seawater. This instrument is based on flow injection analysis with colorimetric detection. Its functionalities have been described in [19]. Briefly, CHEMINI is made of two modules: a hydraulic module and a detection module. The hydraulic module is composed of a pressurized titanium tank filled with dielectric oil (Fluorinert FC 770, 3M, Fig. 2). It contains a mechanically polymethylmetacrylate engraved manifold, two in-house designed peristaltic pumps, and eight solenoid valves (LVM115 from SMC, Japan) for the circulation of various fluids (reagents, standards, samples). The pump tubings are made of Tygon (E3603). The detection container is a titanium tank kept under slight depression ( -0.2 bars). It contains the electronic cards for driving the various actuators (Appli card), recording the LED detection system and storing data (ATMEL ATMEGA). The ATMEGA card had a memory capacity of $8 \mathrm{Mb}$ which can store about 700 complete spectra [19]. For long-term deployment, the capacity was increased to $32 \mathrm{Mb}$ to enable the recording of approximately $2800 \mathrm{spec}-$ tra. The quartz flow cell (3-cm path length, Hellma) is located outside the tank and connected to the LED detection system via optical fibers and special waterproof titanium optical pass through (SEDI, France).

1) Reagents: Reactive iron concentrations [Fe(II)+Fe(III)] are obtained using the ferrozine method. The ferrozine molecule reacts with $\mathrm{Fe}$ (II) to form a magenta complex in the presence of a buffered ascorbic acid solution. The colorimetric detection consists in dual wavelength signal treatment by recording the reference signal $(810 \mathrm{~nm})$ and the measurement signal $(562 \mathrm{~nm}$ 


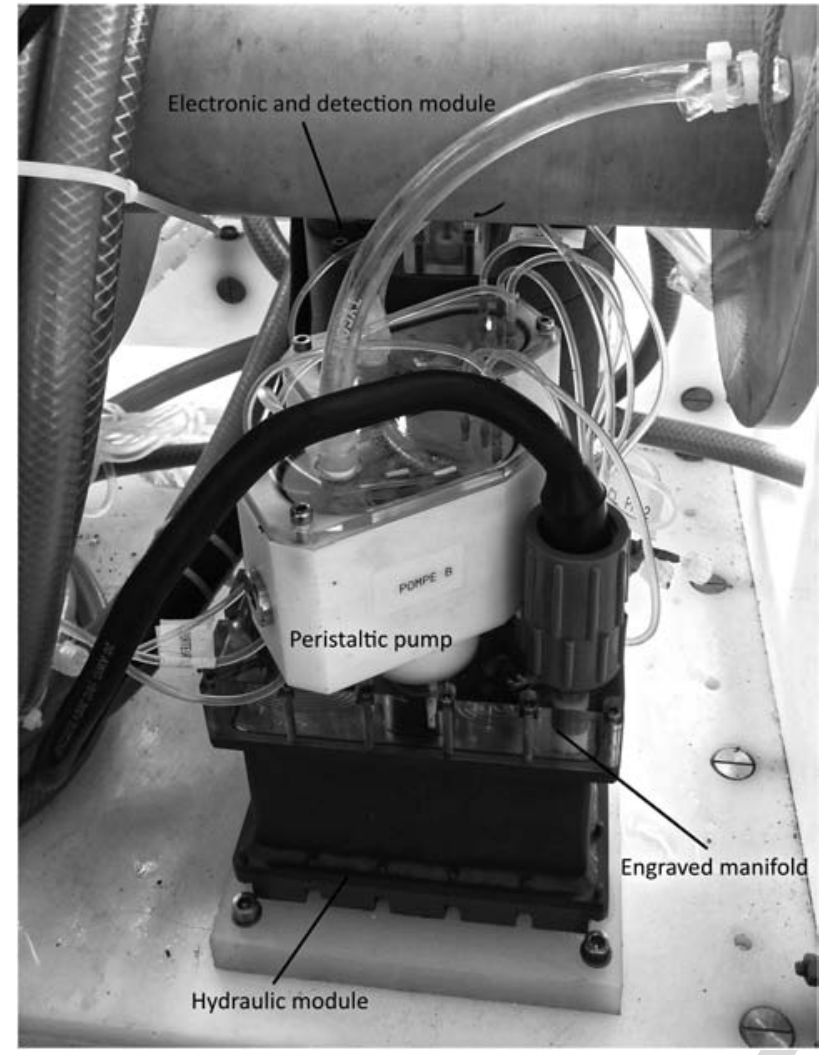

Fig. 2. Hydraulic module of CHEMINI and its implementation on the Tempo module.

[23], [24]). The dual wavelength measurement using LEDs was performed to limit any matrix effects such as turbidity variations.

To avoid any obstruction in the sample stream, blockage, or changes in the flow, the incoming seawater was unfiltered. The iron fraction analyzed using CHEMINI then corresponded to an operationally defined fraction of iron, herein called reactive iron. This fraction included the dissolved and particulate iron in unfiltered seawater that is labile enough to react with ferrozine in the presence of buffered ascorbic acid. The reagents used for the study were the same as described in [19]. The iron (III) solution was prepared with iron (III) chloride $\left(\mathrm{FeCl}_{3} \quad 6 \mathrm{H}_{2} \mathrm{O}\right.$, p.a.Merck) in ultrapure water acidified (1 M) with hydrochloric acid ( $\mathrm{HCl}$, p.a.Merck, 37\%). The day of deployment, the $25 \mu \mathrm{mol} . \mathrm{L}^{-1}$ standard was prepared by dilution of this mother solution in acidified artificial seawater ( $35 \mathrm{~g}$ of sodium chloride $\mathrm{NaCl}$ and $1.5 \mathrm{~mL}$ of $\mathrm{HCl} 6 \mathrm{~N}$ for $1 \mathrm{~L}$ of ultrapure water). The buffer capacity of ascorbic acid was adequate to bring the solution $\mathrm{pH}$ into optimal range for the acidified standard as well as for the un-acidified natural seawater analyzed in situ. The standard solution was introduced in a 5-L plastic bag and stored at $4^{\circ} \mathrm{C}$ until placed in the Tempo drawer. The volumes of the reagents and standard were increased compared with [19]. One year deployment required $10 \mathrm{~L}$ of acidified $\mathrm{NaCl}, 10 \mathrm{~L}$ of ferrozine reagent, $10 \mathrm{~L}$ of ascorbic acid, and $5 \mathrm{~L}$ of $25 \mu \mathrm{mol} . \mathrm{L}^{-1}$ Fe(III) standard solutions. Flexible 5-L bags (Promela, Monaco) were used to store and recover reaction product waste. Once filled, the flexible bags were placed in the Tempo drawer and connected to the manifold of the CHEMINI using Luer connections (Fisher Scientific).

2) Figures of Merit: The performance of CHEMINI in the analysis of reactive iron is described in [19]. CHEMINI has a concentration range from the limit of detection (LOD) [0.3 $\mu$ mol. $\left.\mathrm{L}^{-1}(\mathrm{n}=20)\right]$ to $100 \mu \mathrm{mol} . \mathrm{L}^{-1}$, with a repeatability of $0.6 \%(n=5)$ in the range of concentrations encountered in the studied area.

\section{Calibration and Stability of the Signal}

Before deployment on the MoMAR observatory, CHEMINI was tested both in the laboratory and in a hyperbaric testing tank (March 2013, Ifremer Brest) to validate the stability of the signal under different pressure and temperature conditions and also to confirm the robustness of the instrument.

1) Laboratory Calibration and Stability Signal: Stability signal tests were carried out in the laboratory and especially on the optical detection system of CHEMINI. Five light intensities from the maximum to approximately half-light power were tested. The aim was to simulate degraded light conditions and to determine the limits of the detection system. The five intensities of light were applied for seven days for a $50 \mu$ mol. $\mathrm{L}^{-1}$ iron standard and for 16 days for three iron standards (0, 20 and $60 \mu \mathrm{mol} . \mathrm{L}^{-1}$ ).

2) Hyperbaric Tests: The impact of temperature and pressure variation depends on the nature of the chemical method used in the in situ analyzer but also on instrument structure, including electronic components, reagents, and standards. CHEMINI was tested in a hyperbaric testing tank (Ifremer Brest). Both the electronic and hydraulic modules were immersed; the reagents and standards were placed in flexible bags. The first experiment consisted in increasing the pressure from 10 to 450 bars at an ambient temperature of $17.9^{\circ} \mathrm{C}$. The second experiment tested a decrease in temperature, from $17.9^{\circ} \mathrm{C}$ to $3.6^{\circ} \mathrm{C}$ at a constant pressure of 465 bars.

\section{E. In Situ Sampling Strategy}

Seawater was directly pumped from the environment without any filtration and supplied to the CHEMINI analyzer located on the Tempo structure. The acquisition period for iron determination was twice a day: four replicates at noon for the $25 \mu \mathrm{mol} . \mathrm{L}^{-1}$ iron (III) standard, to correct for possible instrument drift, and four measurements at midnight for the in situ iron sample determination. For each sample measurement, only the last three measurements were considered as representative, the first being discarded (to rinse the system). The dissolved oxygen concentrations and temperature recording with the Aanderaa optode had a resolution of one measurement every $15 \mathrm{~min}$. Data processing, time-series analysis, and power spectral densities were performed using the statistical $R$ platform.

\section{RESULTS AND DISCUSSION}

\section{A. Calibration and Stability of the Signal}

1) Laboratory Calibration and Stability Signal: Results show that regardless of the intensity of light applied to the 
detection system, the absorbance $(A)$ value for the $50 \mu \mathrm{mol} . \mathrm{L}^{-1}$ iron standard did not vary (mean value of $A=0.47525 \pm$ $0.00827)$. Precision was $1.7 \%(n=278)$ for one week, indicating a robust detection module. Moreover, the standard deviation of the calibration slope was $2.2 \%$. This value is close to the repeatability value of $1.4 \%(n=5)$ obtained for concentrations from the LOD up to $100 \mu \mathrm{mol} . \mathrm{L}^{-1}$ [18] and $0.6 \%$ on five $50 \mu \mathrm{mol} . \mathrm{L}^{-1}$ standards [19], under constant light intensity.

2) Hyperbaric Tests: Results from our pressure tank experiment show that as the pressure rose, the maximum absorbance (observed for our $100 \mu \mathrm{mol} . \mathrm{L}^{-1}$ iron standard) remained constant in intensity although peak shape started to broaden. An average delay of $15 \mathrm{~s}$ was calculated for the time at which the maximum absorbance was observed at various tested pressure. Similar broadening was observed for decreasing temperatures. In addition, at constant pressure (465 bars), there was a delay of $26 \mathrm{~s}$ before obtaining maximum absorbance. This delay indicates that the flow rate decreases with an increase in pressure and a decrease in temperature, perhaps due to squeezing in the pump tubing or to pump rotation speed, which may be slower than at the surface. Similarly, other studies using analyzers with peristaltic pumps have reported variation in the calibration slope according to pressure [15], [17].

Thus, the functioning of CHEMINI is highly sensitive to changes in temperature and pressure. To determine an accurate and realistic iron concentration, it is essential to calibrate the system under the same temperature and pressure conditions as the in situ analysis.

\section{B. Deployment on the MoMAR Observatory 2013-2014}

Tempo started its acquisition on August 31, 2013 at 14:45 and stopped functioning due to battery failure on February 23, 2014 at 02:45. In total, 1398 plots of absorbance as a function of time were recorded for CHEMINI and 16778 data points for temperature. The precision of the standard concentration of $25 \mu \mathrm{mol} . \mathrm{L}^{-1}$ $\mathrm{Fe}$ (III) analyzed daily in situ was $1.07 \%(n=522$, three replicates per day), illustrating the satisfactory analytical performance of CHEMINI and validating the in situ iron concentrations obtained. The sample concentration was calculated using the mean standard concentration averaged over the six months of measurement $\left([\mathrm{Fe}]=25.00 \pm 0.27 \mu\right.$ mol. $\left.\mathrm{L}^{-1}, n=522\right)$ as it was extremely stable. Every day, three sample concentrations were obtained; we did not use daily averages because the measurements corresponded to different sampling sequences taken over a 15-min period. The operationally defined fractions of $\mathrm{Fe}$ measured by CHEMINI are not directly comparable to those of the fluid sampled by the ROV, which is in situ filtered and analyzed later in the laboratory using traditional analytical methods. Laboratory measurements provide total dissolved iron (for filtered and acidified samples) or total electrochemical active iron contents (for voltammetric measurements). Despite the methodological differences, our reactive iron concentrations were of the same order of magnitude as those measured using inductively coupled plasma mass spectroscopy (ICP-MS) on discrete samples in 2012 at the same Tour Eiffel site [25]. In fact, an in situ filtered sample was taken simultaneously with a CHEMINI

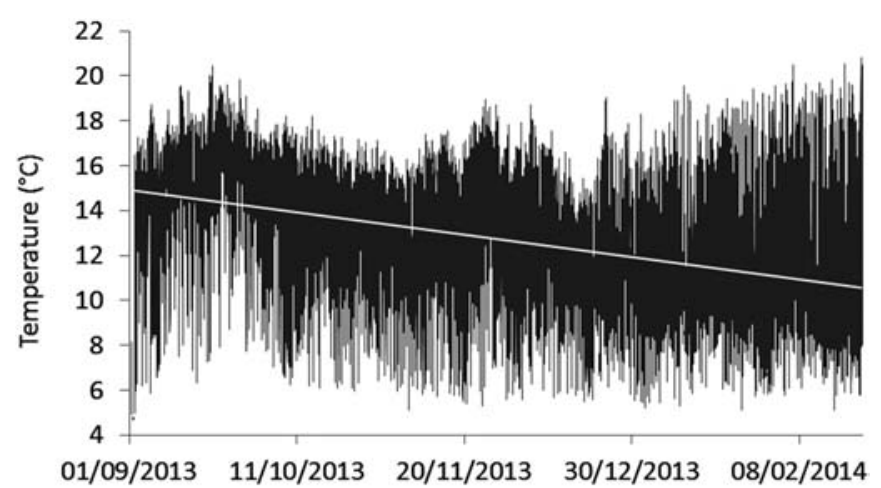

(a)

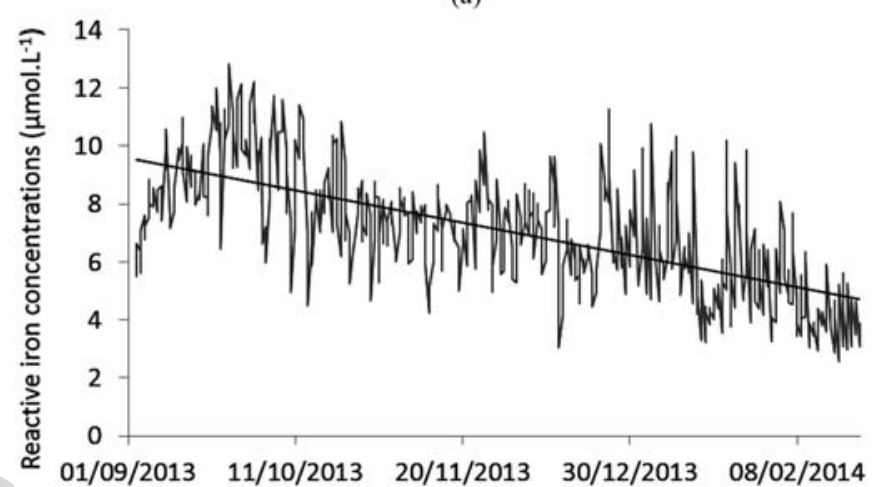

(b)

Fig. 3. Variation in (a) temperature $\left({ }^{\circ} \mathrm{C}, 16108\right.$ data points, sampling period: $15 \mathrm{~min}$ [26]) and (b) reactive iron concentrations $\left(\mu \mathrm{mol}_{\mathrm{L}} \mathrm{L}^{-1}, 517 \mathrm{mea}-\right.$ surements, sampling period: $24 \mathrm{~h}$ [25]) from August 31, 2013 to February 23, $2014\left(\mathrm{~T}^{\circ} \mathrm{C}: y=-0.0247 \pm 0.0004+1041.5 \pm 18.2, R^{2}=0.1656, n=\right.$ $16108, p<0.001$; [Fe]: $y=-0.0278 \pm 0.0014+1164.7 \pm 57.7, R^{2}=$ $0.4373, n=517, p<0.001)$.

measurement on a diffuse vent site at Menez Gwen during the BIOBAZ 2013 cruise (R/V Pourquoi Pas?). The ICP-MS total iron concentrations were $0.3 \pm 0.1 \mu \mathrm{mol} . \mathrm{L}^{-1}$ when CHEMINI measurements gave $0.8 \pm 0.4 \mu \mathrm{mol} . \mathrm{L}^{-1}$ of total reactive iron, giving us confidence that both measurements are comparable. We can reasonably assume that the reactive iron data provided by CHEMINI give a good estimation of the hydrothermal input and its variability on this mussel bed.

The variation of temperature $\left({ }^{\circ} \mathrm{C}\right)$ and reactive iron concentrations ( $\mu \mathrm{mol} . \mathrm{L}^{-1}$ ) from August 31, 2013 to February 23, 2014 are shown in Fig. 3 [26], [27]. A time delay between the iron analysis and the temperature (1-5 min) was observed and avoided synchronization and a direct correlation for every sampled point. The averaged reactive iron concentrations for the six-month period were low $\left([\mathrm{Fe}]=7.12 \pm 2.11 \mu \mathrm{mol} . \mathrm{L}^{-1}\right.$, $n=517$ ), but showed some noticeable variation, with minimal and maximal values of 2.59 and $12.82 \mu \mathrm{mol} . \mathrm{L}^{-1}$, respectively. These values are comparable with those obtained in 2006 in the same study area using the CHEMINI analyzer (from the LOD to $10.2 \mu \mathrm{mol} . \mathrm{L}^{-1}$ [19]). Temperature also showed moderate values $\left(T=12.73 \pm 3.06{ }^{\circ} \mathrm{C}, n=16,108\right)$, with maximum and minimum values of $20.81{ }^{\circ} \mathrm{C}$ and $4.67{ }^{\circ} \mathrm{C}$, respectively, and corresponding to the average conditions for the habitat of the faunal assemblage studied [28], [29]. Variations in temperature and reactive iron showed similar overall patterns. For 


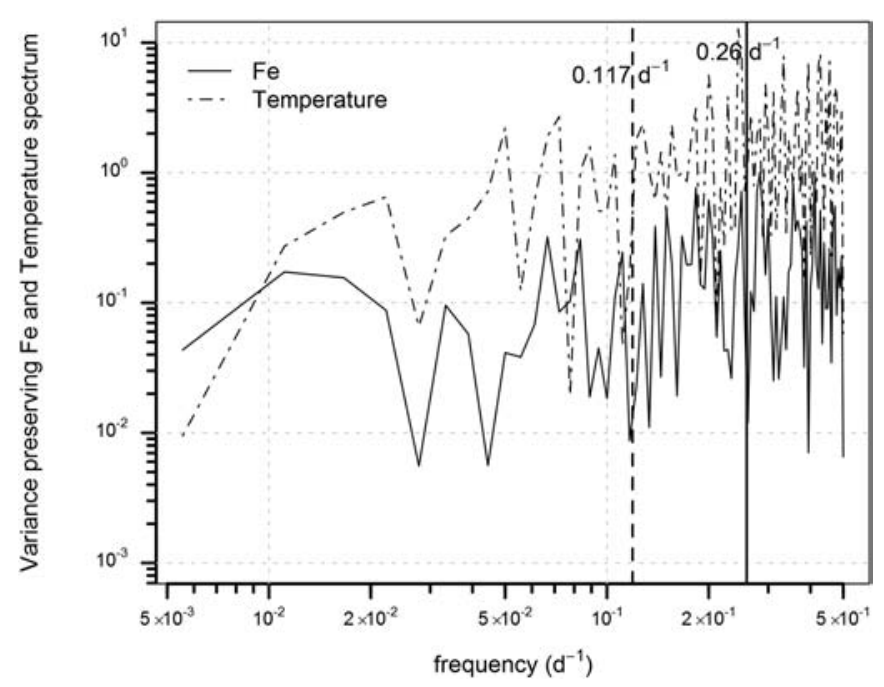

Fig. 4. Plot of temperature (dashed line, $n=519$ ) and reactive iron concentrations (solid line, $n=519$ ) variance-preserving spectra (subdiurnal scale) from August 31, 2013 to February 23, 2014.

example, on September 25, 2013, the temperature increased to $17.91{ }^{\circ} \mathrm{C}$ and total reactive iron also increased, reaching a value of $12.82 \mu \mathrm{mol} . \mathrm{L}^{-1}$. A similar increase also occurred on November 25, 2013 with a temperature of $17.97{ }^{\circ} \mathrm{C}$ and a reactive iron concentration of $10.45 \mu \mathrm{mol} . \mathrm{L}^{-1}$.

Both temperature and reactive iron were statistically correlated with time (Fig. 3). A global decreasing trend was observed for both parameters over the sampling period. This decrease is likely to be related to the widespread decline in diffuse venting over the last 13 years as noted in [30] at Lucky Strike. The decline in diffuse venting has been attributed to an overall reduction in the mass flux of hydrothermal discharge across the vent field, although this explanation lacked support from other sources of measurement. Our results on the Tempo sampling site, characterized by a substrate with many diffuse outflows, appears to corroborate these previous observations of a decline in diffuse venting at Lucky Strike.

Despite this decreasing trend, no episodic events were recorded at the EMSO-Azores observatory for the iron distribution, and no relevant periodicity was observed for temperature at the subdiurnal scale (Fig. 4). Nevertheless, variance-preserving power spectra indicated frequencies of 4.7 and 3.8 days, respectively, for temperature and iron concentrations (Fig. 4). Similar cycles lasting three to four days have been previously detected near seamounts for currents along the crest of the Juan de Fuca Ridge (North Pacific Ocean [31]). Coherence between temperature and currents suggest that four-day oscillations play a major role in the local advection of hydrothermal plumes. In another study, Cuvelier et al. [32] also showed a significant period of 4.5 days for two faunal taxa (Polynoidae and Buccinidae) at the Main Endeavour Field (North Pacific Ocean). However, the processes associated with this four-day frequency are currently unclear. On a diurnal scale, temperature data series showed a significant tidal signal (Fig. 5, $1.9 \mathrm{~d}^{-1}, 3.8 \mathrm{~d}^{-1}$ ), as already noted in [22] and [33] for the same area. Tidal cycles have been

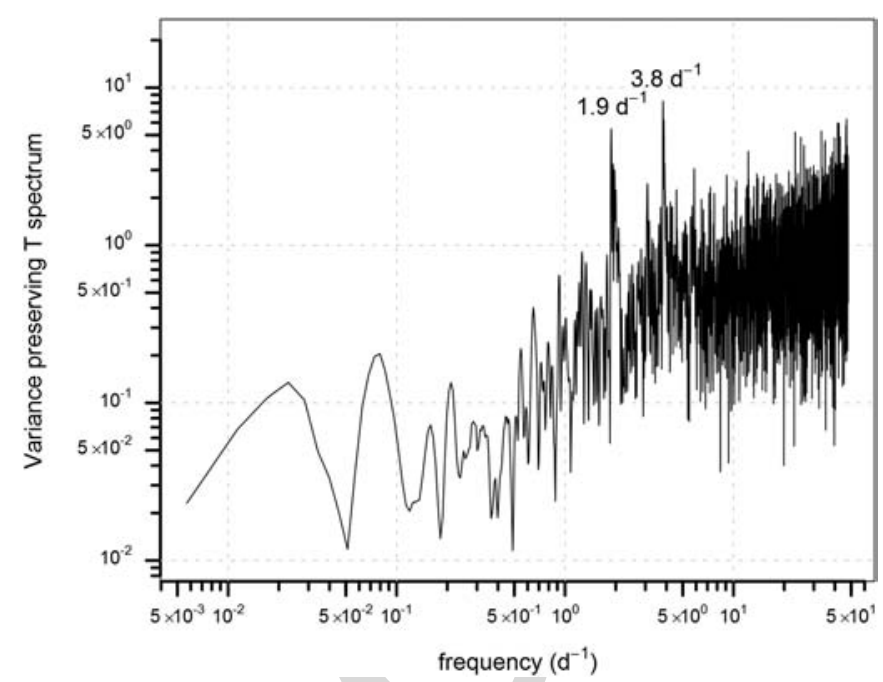

Fig. 5. Plot of temperature variance-preserving spectra (diurnal scale, $n=$ 16 741) from August 31, 2013 to February 23, 2014.

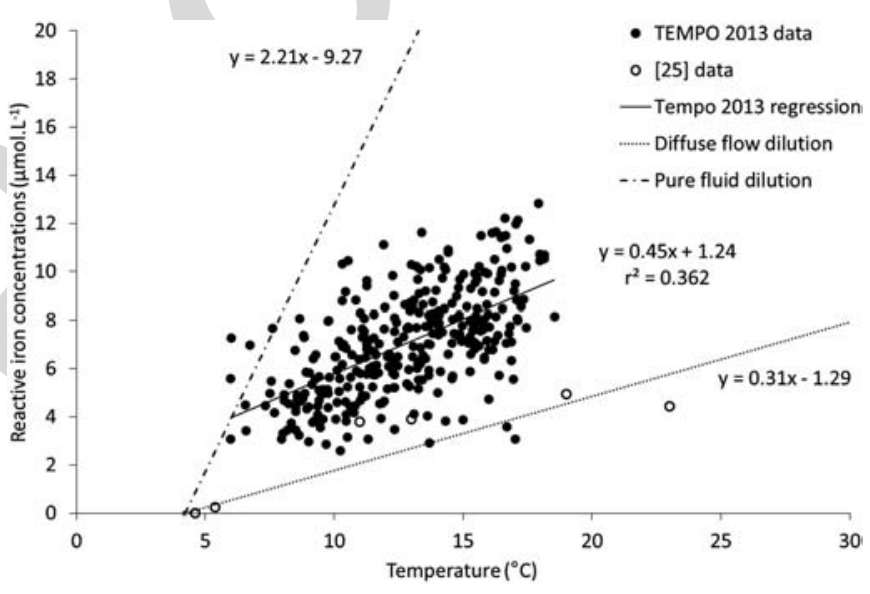

Fig. 6. Plot of temperature $\left({ }^{\circ} \mathrm{C}\right)$ according to reactive iron concentrations ( $\mu$ mol.L ${ }^{-1}$ ) from August 31, 2013 to February 23, 2014. Black circles: observed data; solid black line: linear regression over the observed data points $\left(y=0.45 \pm 0.03 x+1.24 \pm 0.43, R^{2}=0.362, n=330\right)$; white circles: data from [25]; dashed line: theoretical dilution line for diffuse outflow from [25] (see text for more details); dotted-dashed line: theoretical dilution line between pure hydrothermal fluid and seawater calculated from [35].

documented as driving ecological factors in other hydrothermal systems [32], [34].

Even though measurements were not synchronized, temperature and reactive iron concentrations appeared to be significantly correlated (Fig. 6, black dots, $r^{2}=0.362, p<0.001$ ). One should keep in mind that some of this relationship integrates the natural variability of the system. It might also partly reflect the methodological variability of our instrument, although, as mentioned earlier, standard measurements appear very constant over time giving us confidence in the stability of the CHEMINI analyzer. Using the iron concentration determined by [35] in the pure Tour Eiffel hydrothermal fluid and the temperature reported by [33] and [30] for this edifice, we calculated a theoretical dilution line (seawater: $T=4.2{ }^{\circ} \mathrm{C},[\mathrm{Fe}]=$ $0.003 \mu \mathrm{mol} . \mathrm{L}^{-1}$, end-member hydrothermal fluid as in [35] and 
[36] $T=323{ }^{\circ} \mathrm{C},[\mathrm{Fe}]=704 \mu \mathrm{mol} . \mathrm{L}^{-1}$, Fig. 6 , dotted-dashed line). As part of the long-term MoMAR experiment, one study [33] recently observed that the Lucky Strike vent fluid shows stable temperatures over three years of monitoring, with an average hydrothermal fluid temperature of $322.8{ }^{\circ} \mathrm{C} \pm 2.8^{\circ} \mathrm{C}$ between 1993 and 2012. We thus expect little variation in the concentrations of the major elements in the end-member fluid and in the slope of the theoretical dilution line (Fig. 6, dotted-dashed line), ruling out hydrothermal fluid variability as an explanation of the fluctuations and lower slope observed in our data.

We used the iron concentrations measured at the Tempo site in [25] to calculate a second dilution curve (Fig. 6, white dots, dashed line), representing the theoretical mixing between diffuse outflow and seawater (referred hereafter as "diffuse dilution curve"). These measurements were taken in August 2012 from in situ filtered samples along a mixing gradient from a diffuse outflow to the surrounding seawater; therefore, this trend line can be used to represent the iron behavior in the dilution of diffuse venting in seawater. The positive divergence between our data and the diffuse dilution curve could be due to the difference in the iron fraction analyzed in [25] and with CHEMINI, respectively, dissolved and reactive iron (dissolved and a fraction of particulate). However, as explained above, the results obtained for Menez Gwen sample using ICP-MS and CHEMINI were satisfactory, giving us confidence that both measurements are quite comparable; indeed, a significant part of the hydrothermal particulate iron has been lost already in the chimney before being expulsed in seawater [36]. The difference might be due to distinct sampling dates. Still, very few data points follow the diffuse dilution curve, but most of the reactive iron concentrations lie between pure hydrothermal fluid curve and the diffuse venting one. This suggests that the fluid sampled by CHEMINI could originate from simple subseafloor dilution of pure hightemperature fluid by cold pore fluids (Fig. 7, hypothesis 1). Outflow of pure hydrothermal fluid can vary depending on spatial considerations (e.g., variation in seafloor porosity, fracture geometry), leading to additional temporary inputs. Subseafloor chemical transformation processes of the migrating fluid, with differential residence times within the substratum, called the "secondary circulation system," may also occur (Fig. 7, hypothesis 2 [33]). The combination of both types of input as well as additional mixing processes after the diluted fluid has been expelled from the diffuse outflow (tidal pressure and currents) is also possible. At this point of study, we do not have enough information to statute between a pure fluid and a diffuse source of reactive iron in the Tempo area.

Fig. 6 also shows that our data lie below the theoretical dilution line. This variance is mainly due to the precipitation of iron under metal sulfide fraction (pyrite, nanoparticles, etc. [36]) or iron oxy hydroxide particulate minerals [37]. Several other biogeochemical processes can influence the fate of iron in hydrothermal input. In fact, metal speciation associated with nutrient scavenging and bacterial metabolism remove significant amounts of dissolved iron from the aqueous phase [1], [9], [38], [39], usually showing a nonconservative behavior when mixed with oxygenated seawater. A more outstanding feature of Fig. 6 is the apparent conservative behavior of reactive iron in this

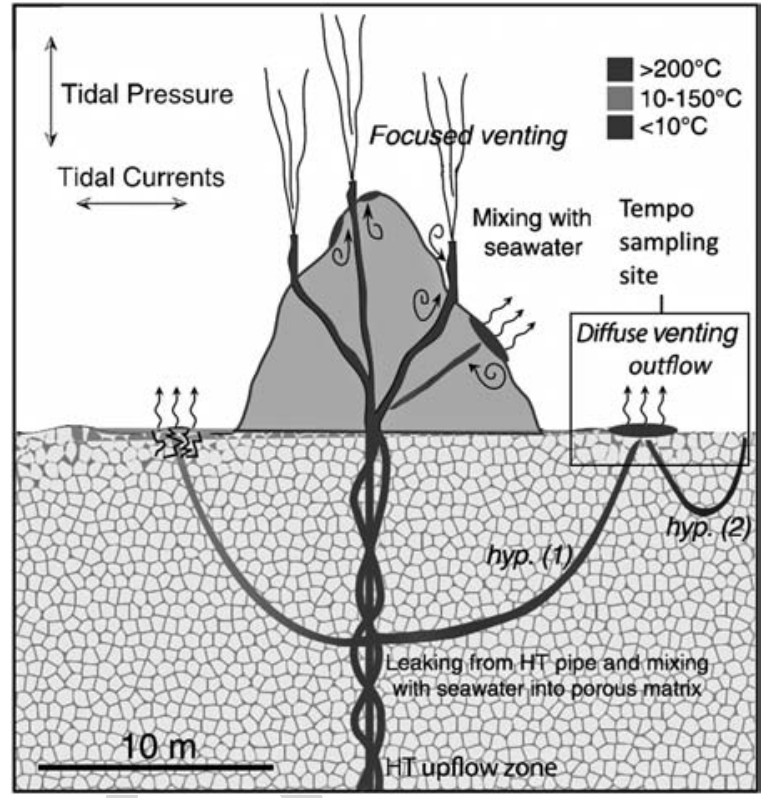

Fig. 7. Conceptual model of a hydrothermal edifice in the eastern part of the Lucky Strike hydrothermal field, modified from [33], shows the location of the Tempo sampling site on the diffuse venting outflow. Hypothesis (1): leakage from the hot temperature $(\mathrm{HT})$ pipe and mixed with cold water into the porous matrix. Hypothesis (2): conductively heated bottom water drawn into the seafloor as part of the secondary circulation system.

temperature range. This suggests stabilization of reactive iron near the diffused vent with inorganic (nanoparticules of pyrite, aggregation of colloidal forms of oxy hydroxide [40], [41]) or organic phases (strong complexing organic ligands [42]) to prevent it from precipitation processes. This would explain the $3.07 \mu \mathrm{mol} . \mathrm{L}^{-1}$ of total reactive iron detected at the Tempo sampling site even at seawater temperature (extrapolation of the Tempo 2013 regression to $4.2{ }^{\circ} \mathrm{C}$ ). Such stabilization processes have already been observed and described in recent studies on hydrothermal plumes [38], [43] or directly in hydrothermal vent systems and chimneys [1], [44]. They tend to compete with the rapid formation of polymetallic sulfides and iron oxyhydroxide, promoting the iron availability to the biological community structure in these singular deep-sea environments. They can also be responsible for iron transport in deep ocean as described in [45] and [46]. Our results emphasize this reactive iron stabilization with organic/inorganic phases probably in a colloidal (aggregates) and/or a particulate form, for a six-month-long deployment. Compared to instantaneous and discrete plume studies, our data represent the first evidence of such stabilization mechanisms in a yearly timescale.

A characterization of the nature of particles [44], a use of in situ sensors dedicated to the analysis of sulfur as well as metal speciation [4], [47]-[49] would be useful to discriminate among all the processes involved and the forcing factors driving the iron concentrations at the Tempo diffuse venting site. Coupling of various long-term in situ analysis techniques would constitute a massive progress in the development of new autonomous scientific instruments for seafloor observatory as 
well as in the understanding of hydrothermal impact on the global metal distribution in the deep ocean.

\section{CONCLUSION}

CHEMINI showed analytical reliability and mechanical robustness over time. This instrument is well suited for long-term in situ monitoring of hydrothermal ecosystems. Tempo collected a representative data series of the chemical environment $\left(\mathrm{T}^{\circ} \mathrm{C}\right.$, reactive $\mathrm{Fe}$ ) at the Lucky Strike vent. This study highlighted significant correlation between temperature and reactive iron. It also provided a long-term survey on this hydrothermal edifice. Nevertheless, low sampling resolution prevented the observation of episodic events, and an increase in sampling period could help specify the relationship between iron concentrations and temperature, as well as the processes involved. Electrical power as well as reagent consumption are limiting factors, and should be carefully taken into consideration to ensure the feasibility of an increase in sampling resolution. The next deployment scheduled in August 2016 will strive to integrate such considerations to acquire accurate data on the temporal variability of hydrothermal vent environments.

Other experiments deployed on the EMSO-Azores MoMAR observatory are currently acquiring longer time series (20102015 and still recording). A thorough statistical treatment of our reactive iron, temperature, and dissolved oxygen data set in association with the video footage recorded by Tempo (currently being processed) will provide insight on hydrothermal faunal communities, their dynamics, and their structuring factors. In a distant future, the addition of in situ sensors dedicated to the analysis of sulfur as well as metal speciation could also be very useful for a thorough chemical identification of the Tempo diffuse venting site.

\section{ACKNOWLEDGMENT}

The authors would like to thank the different captains of oceanographic vessels and their crews for their never-failing collaboration in the success of the EMSO-Azores observatory implementation (PI Mathilde Cannat-CNRS-IPGP). They would also like to acknowledge the Victor 6000 ROV pilots for their patience, constant support, and invaluable help. The authors would like to thank the Tempo engineers and technicians who developed and serviced the observation module: J.-Y. Coail, P. Pichavant, G. Guyader, D. Le Piver, S. Barbot, F. Caradec, P. Rousseaux, L. Gautier, L. Delauney, and S. Le Guillou. They would also like to thank J.-F. Rolin and J. Blandin.

\section{REFERENCES}

[1] S. G. Sander and A. Koschinsky, "Metal flux from hydrothermal vents increased by organic complexation," Nature Geosci., vol. 4, no. 3, pp. 145-150, 2011.

[2] A. Tagliabue et al., "Hydrothermal contribution to the oceanic dissolved iron inventory," Nature Geosci., vol. 3, no. 4, pp. 252-256, 2010.

[3] K. L. Von Damm, "Temporal and compositional diversity in sea-floor hydrothermal fluids," Rev. Geophys., vol. 33, no. Jul., pp. 1297-1305, 1995.

[4] G. W. Luther III et al., "Chemical speciation drives hydrothermal vent ecology," Nature, vol. 410, no. 6830, pp. 813-816, 2001.
[5] D. Desbruyères et al., "Variations in deep-sea hydrothermal vent communities on the Mid-Atlantic Ridge near the Azores plateau," Deep. Res. I, Oceanogr. Res. Papers, vol. 48, no. 5, pp. 1325-1346, 2001.

[6] K. S. Johnson, "In situ measurements of chemical distributions in a deepsea hydrothermal vent field," Science, vol. 231, pp. 1139-1141, 1986.

[7] P.-M. Sarradin et al., "Dissolved and particulate metals (Fe, Zn, Cu, Cd, $\mathrm{Pb}$ ) in two habitats from an active hydrothermal field on the EPR at $13^{\circ}$ N," Sci. Total Environ., vol. 392, no. 1, pp. 119-129, 2008.

[8] A. Gartman, M. Yücel, and G. W. Luther III, "An introduction to the major chemical components released from hydrothermal vents," Reference Module in Earth Systems and Environmental Sciences, Amsterdam, The Netherlands: Elsevier, 2014, pp. 1-11.

[9] B. M. Toner et al., "Preservation of iron(II) by carbon-rich matrices in a hydrothermal plume," Nature Geosci., vol. 2, no. 3, pp. 197-201, 2009.

[10] C. R. German et al., "Hydrothermal Fe cycling and deep ocean organic carbon scavenging: Model-based evidence for significant POC supply to seafloor sediments," Earth Planet. Sci. Lett., vol. 419, pp. 143-153, 2015.

[11] K. S. Johnson, C. L. Beehler, and C. M. Sakamoto-Arnold, "A submersible flow analysis system,” Anal. Chim. Acta, vol. 179, pp. 245-257, 1986.

[12] K. H. Coale, C. S. Chin, G. J. Massoth, K. S. Johnson, and E. T. Baker, "In situ chemical mapping of dissolved iron and manganese in hydrothermal plumes," Nature, vol. 352, no. 6333, pp. 325-328, 1991.

[13] C. S. Chin et al., "In situ observations of dissolved iron and manganese in hydrothermal vent plumes, Juan de Fuca Ridge," J. Geophys. Res., vol. 99, no. B3, pp. 4969-4984, 1994.

[14] K. Okamura et al., "Development of a deep-sea in situ Mn analyzer and its application for hydrothermal plume observation," Mar. Chem., vol. 76, no. 1-2, pp. 17-26, 2001.

[15] N. Le Bris, P. M. Sarradin, D. Birot, and A.-M. Alayse-Danet, "A new chemical analyzer for in situ measurement of nitrate and total sulfide over hydrothermal vent biological communities," Mar. Chem., vol. 72, no. 1, pp. 1-15, 2000.

[16] T. P. Chapin, H. W. Jannasch, and K. S. Johnson, "In situ osmotic analyzer for the year-long continuous determination of $\mathrm{Fe}$ in hydrothermal systems," Anal. Chim. Acta, vol. 463, no. 2, pp. 265-274, 2002.

[17] A. Laës et al., "Impact of environmental factors on in situ determination of iron in seawater by flow injection analysis," Mar. Chem., vol. 97, no. 3-4, pp. 347-356, 2005.

[18] P. M. Sarradin, N. Le Bris, C. Le Gall, and P. Rodier, "Fe analysis by the ferrozine method: Adaptation to FIA towards in situ analysis in hydrothermal environment," Talanta, vol. 66, no. 5, pp. 1131-1138, 2005.

[19] R. Vuillemin et al., "CHEMINI: A new in situ CHEmical MINIaturized analyzer," Deep. Res. I, Oceanogr. Res. Pap., vol. 56, no. 8 , pp. 1391-1399, 2009.

[20] A. Colaço et al., "MoMAR-D: A technological challenge to monitor the dynamics of the Lucky Strike vent ecosystem," ICES J. Mar. Sci., vol. 68 , no. 2 , pp. 416-424, 2011.

[21] A. Laës-Huon et al., "Long term in situ monitoring of total dissolved iron concentrations on the MoMAR observatory," in Proc. IEEE Sensor Syst. Changing Ocean, Brest, France, 2014, DOI: 10.1109/SSCO.2014.7000366.

[22] J. Sarrazin, D. Cuvelier, L. Peton, P. Legendre, and P.-M. Sarradin "High-resolution dynamics of a deep-sea hydrothermal mussel assemblage monitored by the EMSO-Açores MoMAR observatory," Deep. Res. I, Oceanogr. Res. Papers, vol. 90, no. 1, pp. 62-75, 2014.

[23] A. Daniel, D. Birot, M. Lehaitre, and J. Poncin, "Characterization and reduction of interferences in flow-injection analysis for the in situ determination of nitrate and nitrite in seawater," Anal. Chim. Acta, vol. 308, pp. 413-424, 1995.

[24] E. A. G. Zagatto, M. A. Z. Arruda, A. O. Jacintho, and I. L. Mattos, "Compensation of the Schlieren effect in flow-injection analysis by using dual-wavelength spectrophotometry," Anal. Chim. Acta, vol. 234, pp. 153$160,1990$.

[25] L. Cotte et al., "A comparison of in situ vs. ex situ filtration methods on the assessment of dissolved and particulate metals at hydrothermal vents," Deep. Res. I, Oceanogr. Res. Papers, vol. 105, pp. 186-194, 2015.

[26] A. Laës-Huon, P.-M. Sarradin, and M. Cannat, "CHEMINI total dissolved iron concentrations $(\mu \mathrm{mol} / \mathrm{l})$ from the EMSO-Azores seafloor observatory, 2013-2014," SISMER, 2015, http://sextant.ifremer.fr/record/1638c611fa3c-4a47-97a8-3f8756f6540f/

[27] P.-M. Sarradin, J. Legrand, and M. Cannat, "Temperature $\left({ }^{\circ} \mathrm{C}\right)$ and dissolved oxygen concentrations $(\mu \mathrm{mol} / \mathrm{l})$ data from the EMSOAzores seafloor observatory, 2013-2014," SISMER, 2015, http:// sextant.ifremer.fr/record/54b837a1-fe5b-441c-87af-270a15b36645/ 
[28] D. Cuvelier et al., "Hydrothermal faunal assemblages and habitat characterisation at the Eiffel Tower edifice (Lucky Strike, Mid-Atlantic Ridge),' Mar. Ecol., vol. 32, no. 2, pp. 243-255, 2011.

[29] J. Sarrazin et al., "Biodiversity patterns, environmental drivers and indicator species on a high-temperature hydrothermal edifice, mid-Atlantic ridge," Deep Sea Res. II, Topical Studies Oceanogr., vol. 121, pp. 177-192, 2015.

[30] T. Barreyre et al., "Structure, temporal evolution, and heat flux estimates from the Lucky Strike deep-sea hydrothermal field derived from seafloor image mosaics," Geochem. Geophys. Geosyst., vol. 13, no. 4, pp. 1-29, 2012.

[31] G. A. Cannon and R. E. Thomson, "Characteristics of 4-day oscillations trapped by the Juan de Fuca Ridge," Geophys. Res. Lett., vol. 23, no. 13, pp. 1613-1616, 1996.

[32] D. Cuvelier, P. Legendre, A. Laës, P. M. Sarradin, and J. Sarrazin, "Rhythms and community dynamics of a hydrothermal tubeworm assemblage at main endeavour field-A multidisciplinary deep-sea observatory approach," PLoS One, vol. 9, no. 5, pp. 62-75, 2014.

[33] T. Barreyre et al., "Temporal variability and tidal modulation of hydrothermal exit-fluid temperatures at the Lucky Strike deep-sea vent field Mid-Atlantic ridge," J. Geophys. Res., Solid Earth, vol. 119, no. 4, pp. 2543-2566, 2014

[34] C. L. Van Dover, "Impacts of anthropogenic disturbances at deep-sea hydrothermal vent ecosystems: A review," Mar. Environ. Res., vol. 102, pp. 59-72, 2014

[35] J.-L. Charlou et al., "Compared geochemical signatures and the evolution of Menez Gwen ( $\left.35^{\circ} 50 \mathrm{~N}\right)$ and Lucky Strike ( $\left.37^{\circ} 17 \mathrm{~N}\right)$ hydrothermal fluids, south of the Azores triple junction on the Mid-Atlantic Ridge," Chem. Geol., vol. 171, no. 1-2, pp. 49-75, 2000.

[36] J. A. Breier et al., "Sulfur, sulfides, oxides and organic matter aggregated in submarine hydrothermal plumes at $9^{\circ} 50$ ' N East Pacific Rise,' Geochim. Cosmochim. Acta, vol. 88, pp. 216-236, 2012.

[37] M. P. Field and R. M. Sherrell, "Dissolved and particulate Fe in a hydrothermal plume at $9^{\circ} 45^{\prime} \mathrm{N}$, East Pacific Rise," Geochim. Cosmochim. Acta, vol. 64, no. 4, pp. 619-628, 2000.

[38] J. A. Hawkes, D. P. Connelly, M. Gledhill, and E. P. Achterberg, "The stabilisation and transportation of dissolved iron from high temperature hydrothermal vent systems," Earth Planet. Sci. Lett., vol. 375, pp. 280 290, 2013.

[39] P. M. Sarradin et al., "Speciation of dissolved copper within an active hydrothermal edifice on the Lucky Strike vent field (MAR, $37^{\circ} \mathrm{N}$ )," Sci. Total Environ., vol. 407, no. 2, pp. 869-878, 2009.

[40] M. Yücel, A. Gartman, C. S. Chan, and G. W. Luther, "Hydrothermal vents as a kinetically stable source of iron-sulphide-bearing nanoparticles to the ocean," Nature Geosci., vol. 4, no. 6, pp. 367-371, 2011.

[41] C. M. Sands, D. P. Connelly, P. J. Statham, and C. R. German, "Size fractionation of trace metals in the Edmond hydrothermal plume, Central Indian Ocean," Earth Planet. Sci. Lett., vol. 319-320, pp. 15-22, 2012.

[42] M. Li et al., "Microbial iron uptake as a mechanism for dispers ing iron from deep-sea hydrothermal vents," Nature Commun., vol. 5, pp. 3192-3200, 2014

[43] S. A. Bennett et al., "The distribution and stabilisation of dissolved Fe in deep-sea hydrothermal plumes," Earth Planet. Sci. Lett., vol. 270, no. 3-4, pp. 157-167, 2008.

[44] B. M. Toner et al., "Biogenic iron oxyhydroxide formation at mid-ocean ridge hydrothermal vents: Juan de Fuca Ridge," Geochim. Cosmochim. Acta, vol. 73, no. 2, pp. 388-403, 2009

[45] T. M. Conway and S. G. John, "Quantification of dissolved iron sources to the North Atlantic Ocean," Nature, vol. 511, no. 7508, pp. 212-215, 2014.

[46] J. A. Resing et al., "Basin-scale transport of hydrothermal dissolved metals across the South Pacific Ocean," Nature, vol. 523, no. 7559, pp. 200-203, 2015.

[47] K. M. Mullaugh et al., "Voltammetric (micro)electrodes for the in situ study of $\mathrm{Fe}^{2+}$ oxidation kinetics in hot springs and $\mathrm{S}_{2} \mathrm{O}_{3}^{2-}$ production at hydrothermal vents," Electroanalysis, vol. 20, no. 3, pp. 280-290, 2008.

[48] K. Ding and W. E. Seyfried, "In situ measurement of pH and dissolved $\mathrm{H}_{2}$ in mid-ocean ridge hydrothermal fluids at elevated temperatures and pressures," Chem. Rev., vol. 107, no. 2, pp. 601-622, 2007.

[49] K. Ding, W. E. Seyfried, M. K. Tivey, and A. M. Bradley, "In situ measurement of dissolved $\mathrm{H}_{2}$ and $\mathrm{H}_{2} \mathrm{~S}$ in high-temperature hydrothermal vent fluids at the main endeavour field, Juan de Fuca Ridge," Earth Planet. Sci. Lett., vol. 186, no. 3-4, pp. 417-425, 2001.

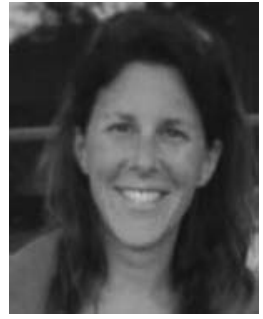

Agathe Laës-Huon received the B.Sc. degree in environmental chemistry (Astra-Zeneca prize) and the M.Sc. degree in chemistry (first grade, "Best performance" prize) from the University of Plymouth, Plymouth, U.K., in 1999 and 2000, respectively, and the $\mathrm{Ph} . \mathrm{D}$. degree in ocean chemistry from the European Institute for Marine Studies (IUEM), Brest, France, in 2004.

In 2007, she joined the an analytical laboratory of the Centre of Documentation, Research and Experimentation on Accidental Water Pollution (Cedre), Brest, France as a Research Scientist. Since 2008, she has been a Research Scientist at the Research and Technological Development Laboratory, Ifremer, Brest, France. Her research interests include analytical chemistry dedicated to seawater and development of in situ instrumentation for monitoring marine chemicals and pollutants (in situ chemical analyzers CHEMINI, in situ extraction and water sampling).

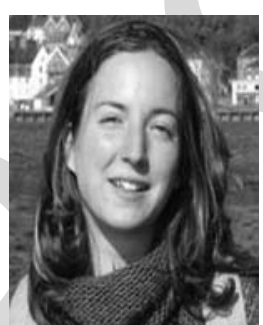

Cécile Cathalot was born in Martigues, France, in 1984. She received the B.Sc. and M.Sc. degrees in water and waste water engineering from the French National Engineering School for Water and Environment (Ecole Nationale du Génie de l'Eau et de l'Environnement de Strasbourg, ENGEES), Strasbourg, France, in 2006 and the Ph.D. degree in environmental sciences (specialty: marine biogeochemisty) from Pierre et Marie Curie University, Paris VI, France, in 2009.

From 2010 to 2012, she was a Postdoctoral Research Assistant within the Ecosystem Studies Department, The Netherlands Institute for Sea Research (NIOZ), Yerseke, The Netherlands. From 2012 to 2014, she worked as a Research Assistant at the Deep-Sea Environment Laboratory, Ifremer, Brest, France. Since 2014, she has been a Research Scientist at the Laboratory of Geophysical Cycles at Ifremer-Brest. She is the author of more than ten papers, and ten oral and poster communications. Her research interests include marine biogeochemical processes both in hydrothermal vents and sedimentary environments and the development of in situ tools for monitoring benthic fluxes and biogeochemical species (eddy correlation, electrochemical microsensors, in situ chemical analysis and water sampling).

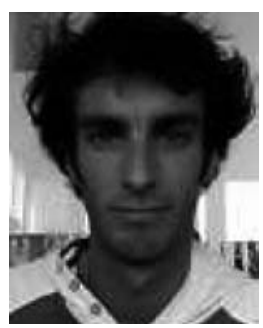

Julien Legrand received the M.Sc. degree in electronics and communication systems from the French National Institute for Applied Sciences (Institut National des Sciences Appliquées de Rennes, INSA), Rennes, France, in 2002.

He joined Ifremer, Brest, France, in 2004 as an Electronics Engineer in the Research and Technological Development Laboratory. After working on marine electronic systems and very low power equipment, he is now in charge of designing electronics cores for deep-sea observatories. He designed one of the hydrothermal vent observatory node package for the Ocean Networks Canada cabled infrastructure and for the standalone node of the EMSO-Azores observatory. He is currently participating in the development of the new electronics core for noncabled observatories. He is the Technical Supervisor of ESMO-Azores observatory and the Ifremer technical contact for Ocean Network Canada. 


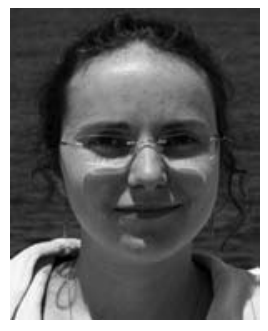

Virginie Tanguy received the $\mathrm{Ph} . \mathrm{D}$. degree in marine chemistry from the European Institute for Marine Studies (IUEM), Brest, France, in 2011, under the supervision of R. D. Riso.

Her research involves the chemical characterization of hydrothermal environments and the study of colloidal speciation of trace metal elements in estuarine systems. From 2010 to 2011, she worked as a Research Scientist at the Deep-Sea Environment Laboratory (LEP), Ifremer, Brest, France. From 2011 to 2013, she was a temporary Teaching and Research Fellow in Chemistry at the University Institute of Technology, Brest, France and at the Marine Environmental Sciences Laboratory (LEMAR) at IUEM.

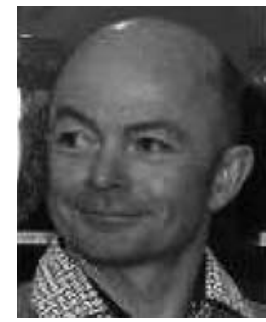

Pierre-Marie Sarradin received the Ph.D. degree in chemistry and microbiology of water from the University of Pau and Pays de 1'Adour, Pau, France, in 1993.

After a temporary teaching and research fellowship position at the same university, he joined the Deep-Sea Environment Laboratory, Ifremer, Brest, France, in 1994. In 2009, he became the head of the Deep-Sea Ecosystem Research Unit (Ifremer, IC EDROME, REM). He coordinated the EXOCET/D European program (2004-2007); he is an active member of Labex Mer and the EMSO France group. Together with M. Cannat (Institut de Physique du Globe, Paris, France) and J. Blandin (Ifremer), he coordinates the EMSO-Azores deep-sea observatory. He has been Chief Scientist of several cruises on the mid-Atlantic Ridge hydrothermal vents. His research interests are centered on deep-sea hydrothermal ecosystems and particularly the chemical characterization of the mixing zone between hydrothermal fluid and seawater, the understanding of the biotic and abiotic factors controlling the distribution of the fauna colonizing hydrothermal vents and their temporal dynamics. 